\title{
STRATEGIC APPROACHES TO MENU TRANSLATION ANALYSIS
}

\author{
Alenka Šuljić Petrc \\ Krešimir Mikinac \\ Ivana Edmonds
}

https://doi.org/10.20867/tosee.05.31

\begin{abstract}
The purpose of this research is to analyse the current quality of menu translations in restaurants in the Kvarner Region and to define the role of menus as a sales tool which can effectively influence on restaurant's image and profit. The aim of this research is to answer the question of how quality translated menus can help and contribute to better business and achieving customer satisfaction. In this research the existing theories and models of translation strategies were analyzed, among which a model for translation strategies that would be applicable to the Kvarner's restaurants. The research also used analytical methods based on sources obtained through a desk research, qualitative and quantitative methods to gather an in-depth understanding of how the existent restaurant menus are translated, while analyzing their quality and finding the possibility of eventual improvement.

The conclusion is that the menu's aims consider communication and sales purposes, as well as achieving customer satisfaction. According to these objectives, the improvement of restaurant menu translations in foreign languages is needed. Quality translated menus are also a reflection of restaurant's image since they still serve the purpose of a business card that with its design, print, size, food, and facility information represent a symbol of restaurant's identity and theme.

The main contribution of the paper is the analysis of menu translations and present strategies for translating which influence service quality and customer satisfaction. The research findings are an important contribution to future research of menu translations and restaurant offer in the Kvarner Region's restaurants.
\end{abstract}

Keywords menu, translation strategies, customer satisfaction, restaurant, sales increase

\section{INTRODUCTION}

Generally, in today's cosmopolitan society, the interest for gastronomy has been growing and as a consequence, there is an increase in interest for translating a variety of cookbooks, culinary TV shows, movies, tourist brochures with culinary experiences, recommendations and restaurant menus. Translations of different texts where the main topic is gastronomy, still remain little explored, therefore, the quality of translations of such texts is often questionable. Menus have a great importance for the business of a restaurant. They represent the initial experience of food enjoyment and leave one of the first impressions on a customer. According to McCall \& Lynn (2008), menu descriptions should be carefully constructed to stimulate the customer's perception of quality, prices and no intention of spending. 
ToSEE - Tourism in Southern and Eastern Europe, Vol. 5, pp. 689-703, 2019

A. Šuljić Petrc, K. Mikinac, I. Edmonds: STRATEGIC APPROACHES TO MENU TRANSLATION ...

The primary purpose of creating a menu is communication. Sensibly selected words can make fascinating and unforgettable impression, which also transfers to menus. A welldesigned menu is a map that navigates the customer to reach their satisfaction and exceed their expectation. Menus are also a reflection of the restaurant's image. There are different aspects of well-designed menus. These aspects include an easy and straightforward language use, precise and accurate description of nutritional information, food preparation and cooking methods, and they clearly show to a customer approximately how much are they likely to spend and whether any additional charges might be added.

The fact is that most of the restaurants are successful because of the loyal and satisfied customer base. If customers are satisfied, it automatically increases a restaurant's profit.

\section{THEORETICAL BACKROUND}

In a modern society multilinguism plays an important role because that kind of communication serves the needs of different languages and nations (Vorajaroensri, 2002) and language represents an essential means for humans to understand the world (Gleitman \& Papafragou, 2005; Hongyang, 2017). It is not only about different languages but it helps in the process of interchanging cultures. Translations of restaurant menus consists of it all, including its characteristic as a communication tool. There are many different perspectives through which the role of translated menus was discussed and the authors have chosen some of the most important ones for this research.

A direct contact with a customer is realized verbally for which tourist workers' knowledge of foreign languages is necessary. Through the direct contact with guests, they have the ability to leave a positive impression. This will allow the same customer to return to the destination or to that hospitability facility. Apart from the verbal contact with employees, menus in hospitability facilities still serve the purpose of a business card that with its design, print, size, food and facility information, and multilingualism is a symbol of restaurant's identity and theme. Customers' expectations, according to Walters, are reflective of the product's physical component, and the image a customer retains about the product depends partially on how that product is interpreted (Walters, 1978). The first phase of a customer's product interpretation begins with the examination of restaurants menus exploring the meal list while expecting comprehensible language and explanations. The unclear translations cause a wrong choice in guest's selection, which in most cases, causes a guest not to return. A restaurant offer is one of the essential elements of the entire tourist experience. The second phase can be considered a contact between restaurant's employees and customers. Restaurant menus offer the possibility for customers and restaurant employees to have direct contact. Through the direct contact with customers, they have the ability to leave positive impression allowing the same customer to return to the tourist destination or to that hospitality facility.

According to Bowen and Morris (1995), a menu becomes an extension of the restaurant's personality. Furthermore, they also define menu's objectives which include communication, providing tangible evidence and sales. A careful word selection in the 
ToSEE - Tourism in Southern and Eastern Europe, Vol. 5, pp. 689-703, 2019

A. Šljić Petrc, K. Mikinac, I. Edmonds: STRATEGIC APPROACHES TO MENU TRANSLATION ...

source language also implies the necessity of the correct terminology choice in the target languages.

There are several researchers who ephasize two main functions of menus: to inform and to attract (Al-Rushaidi and Ali, 2017). Customers become informed about a restaurant offer through a menu, while at the same time they are tempted to make a choice.

A quality menu translation implies functionality of translations of such texts, which is truly needed since the question is about texts that constitute the key element for further communication process between a client and employees. Of course, the only purpose of the translated menus is not just to be a communication tool which will be used by customers and hosts, but to facilitate processes in tourism and consumerism in general (Li, 2019). An intercessory role of translation in tourism is shown as a very important factor in the tourism sector (Munoz, 2011). The authors emphasize the importance of appropriate tourist text translations that require mastery of a specialized language of the profession as one of the essential prerequisites for the quality. This establishes the communication between tourism workers and customers. The menus' contents affect the reaction of the customers' conclusions on the basis of simple rules and personal decision. These contents should be translated into multiple languages in a way that are just as appealing as the original in order to attract customers from different countries and cultures. In this way, the customers would feel more comfortable reading about food in their own language, and the waiters would have a tool that would make it easier to communicate with their customers.

A quality translated restaurant menu inevitably creates a bond with a tourist who wants to experience a different cuisine, unfamiliar flavors, but also on top of that, to exactly understand what he/she is eating. Pouget compares the menus that are translated by professional translators and those that are translated by inadequte translators in Spain. Her research included over thousand menus. There is one part of the translations from Spanish to English language which were made by the professional translators within a certain period of time. This period was followed by a period in which they were translated by inadequate translators. It just shows how the English language became more internationally used, and people felt safer while they were using it. It is because of this that the amount of professional translation was reduced believing that inadequate translations are good enough. Consequently, Pouget (2000) states that translators are being confronted with problems such as culture-specific concepts, as well as very often semantically complex words and terms in their original language. On that track, Trostler and Gvion (2007) define restaurants as institutions which are oriented towars a client, while their menus represent a list of food, or the repertoire that serves to attract clientele. In fact, the purpose and the goal of hospitality facility, especially in the tourist destinations, is to attract the potential customers and to create the quality competition with other hospitlity facilities.

In their literature review on restaurant menus, Ozdemir and Caliskan (2014) stated that the dominant position of menus is in restaurant firms, since it is the core of food and beverage operations. Besides that, they highlight some essential roles of the menu, seen as an instructor that clearly dictates what will be produced, what type of equipment and ingredients are needed, and what qualifications employees should have. Furthermore, a 
ToSEE - Tourism in Southern and Eastern Europe, Vol. 5, pp. 689-703, 2019

A. Šuljić Petrc, K. Mikinac, I. Edmonds: STRATEGIC APPROACHES TO MENU TRANSLATION ...

menu represents a communicating and selling tool which does not mean only the written representation of food and beverage offer, but it also represents the image of a restaurant/firm. According to the same authors, a menu is a base on which customers make their food choices.

Translating restaurant menus is a delicate process for professional translators and many authors proposed some of them. Among the most common ones are the cultural strategies postulated by Venuti (1995) which are considered as two basic translation strategies: foreignisation strategy and domestication strategy. The first one is used by the translators who are trying to adjust the reader to the source culture and it tries to facilitate cultural and linguistic differences for readers (Lindfors, 2001). In this way, the translator breaks the conventions allinating himself/herself from the original. The former strategy, according Munday, uses a transparent, fluent and invisible style in order to minimize the foreigness of the target text and leading the text to be familiar and recognizable (Munday 2008 , p. 144). Both strategies are trying to connect different languages and cultures considering the influence of cultural and ideological factors on translation and the influence of translation on the target readers and cultures as well.

Except of above metioned basic translation strategies, the rest of existent strategies are mostly focused on putting together differences in lanuages and cultures that very often lead to cross-cultural communication that every professional translator has to be aware of.

Recently, there have been many reserachers who explore the importance of menu in attracting and satisfying cutomers. Moreover, they noticed that taking care of a professional menu design that would focus on print, size, food and facility information, could significantly influence the success of a restaurant. The restaurants' competitiveness is one of many managerial issues which could be solved, according to Ozdemir and Caliskan, in creating a menu that would offer a unique meal experience while assuring customer satisfaction.

At the end, a multilingually translated menu quality, as an important element in creating the image of catering, requires a deeper understanding of menus' psychology besides their design, shape and the material on which they are printed. A menu is an essential document that is given to a foreign customer, and their low-quality translation could cause unintended consequences that could move from laughing, unwanted misunderstanding to bad publicity of the hospitality facility (Reynolds, Merritt and Pinckney, 2005).

\subsection{Objectives}

This research is just the first step where the authors are trying to ephasize the importance of quality menu translations which may influence customer's satisfaction and, parallely, their significant influence on the sales increase. The purpose of this research is to analyse the current quality of menu translations in restaurants of the Kvarner Region - Opatija and to define the role of menus as a sales tool which may effectively influence on restaurant's image and profit. Mills and Thomas claim that understanding of customers' expectations is viewed as an interpretation process by which customers make sense of 
ToSEE - Tourism in Southern and Eastern Europe, Vol. 5, pp. 689-703, 2019

A. Šuljić Petrc, K. Mikinac, I. Edmonds: STRATEGIC APPROACHES TO MENU TRANSLATION ...

the restaurant environment, which is an integral part for a restaurant's success. Moreover, they backup this statement with the definition from the Webster's Online Dictionary (2019) where customers are defined as "persons having some specified distinctive characteristics that purchase a service or commodity." By analyzing the available research, direct and indirect consequences of unprofessional translations are apparent, resulting in incomprehensible text of a restaurant offer (Mills and Thomas, 2008). The aim of this research is to answer the question of how quality translated menus could help and contribute to better business and achieving customers' satisfaction.

\section{METHODOLOGY}

\subsection{Accumulation of data}

Data collection depended on availability of menus. Some menus in Croatian and English languages were possible to find on the restaurants' websites or Facebook profiles, but several of them the authors needed to obtain directly by contacting the restaurants' owners or managers.

Figure 1: Research sample

\begin{tabular}{|c|c|c|c|c|c|}
\hline \multirow{2}{*}{$\begin{array}{c}\text { Restaurant's } \\
\text { name }\end{array}$} & \multicolumn{2}{|c|}{$\begin{array}{c}\text { Restaurant } \\
\text { type }\end{array}$} & \multirow{2}{*}{$\begin{array}{l}\text { Review } \\
\text { number }\end{array}$} & \multirow{2}{*}{$\begin{array}{c}\text { Score } \\
\text { (out of } 5)\end{array}$} & \multirow{2}{*}{$\begin{array}{c}\text { Position } \\
\text { (out of 75) }\end{array}$} \\
\hline & $\begin{array}{c}\text { Fine } \\
\text { dining }\end{array}$ & $\begin{array}{l}\text { Local } \\
\text { cuisine }\end{array}$ & & & \\
\hline Argonauti & + & & 41 & 4.5 & 29 \\
\hline Bevanda & + & & 449 & 4 & 11 \\
\hline Bistro Yacht Club & & + & 266 & 4 & 14 \\
\hline Konoba Tramerka & & + & 431 & 4.5 & 3 \\
\hline Laurus & + & & 185 & 4.5 & 5 \\
\hline Moho & & + & 205 & 4.5 & 6 \\
\hline $\begin{array}{c}\text { Remisens Premium } \\
\text { Hotel Kvarner }\end{array}$ & + & & 16 & 4.5 & 49 \\
\hline Roko & & + & 1942 & 4.5 & 2 \\
\hline Ružmarin & & + & 1566 & 4.5 & 4 \\
\hline Stancija Kovačić & + & & 122 & 4.5 & 61 \\
\hline Valle Losca & & + & 660 & 4.5 & 1 \\
\hline
\end{tabular}

The data in Figure 1 are obtained from 11 restaurants in Opatija that are considered the best Opatija's restaurants in 2018 according the Trip Advisor (2019): Bistro Yacht Club, Moho, Bevanda, Ružmarin, Valle Losca, Argonauti, Roko, Stancija Kovačić, Laurus, Konoba Tramerka and Remisens Premium Hotel Kvarner. Out of 75 restaurants classified in different cathegories, the authors have chosen the best restaurants according to the price (Fine Dining: Argonauti, Bevanda, Laurus, Remisens Premium Hotel Kvarner and Stancija Kovačić) and restaurants good for particular features (Local Cuisine: Bistro Yacht Club, Konoba Tramerka, Moho, Roko, Ružmarin and Valle Losca). 
ToSEE - Tourism in Southern and Eastern Europe, Vol. 5, pp. 689-703, 2019

A. Šuljić Petrc, K. Mikinac, I. Edmonds: STRATEGIC APPROACHES TO MENU TRANSLATION ...

The selection was made taking in consideration the number of reviews (each restaurant needed to have more than 100 reviews except for the restaurant Argonauti that had 41 reviews and Remisens Premium Hotel Kvarner 16 reviews considering their 5-star classification and particular type of customers) and scores (minimum 4 out of 5).

The Fine Dining restaurants have lower rate of reviews probably because they are defined as expensive restaurants. Their reviews range from 16 up to 449 reviews and 4 out of 5 have the same score (4.5). On the other hand, Local Cuisine restaurants surpass 200 reviews and 5 out of 6 have the same score (4.5).

Regarding the position of the above mentioned restaurants, the Local Cuisine restaurants are placed better - they occupy positions from 1 to 14, whilst the Fine Dining restaurants are placed from 5 to 61

\subsection{The menu translation analysis}

Providing customers with high-quality service includes the ability to communicate in multiple languages, recognizing the expectations, deeper knowledge of customers' culture origins, and understanding of the several characteristics, etc.

Communication with customers is the most important one, therefore quality translation of menus is crucial. If communication is conducted properly, then it can be the best advertising for a business to gain more profit. In a case where there is no proper communication, a loss procedes. Hence one should be more careful in this communication process.

The menu translation analysis in this research was mainly focused on trying to find translations that are insufficient for the complete understanding of a restaurant offer, lacking the additional description to better understand ingredients, meal preparation, and taste.

\subsubsection{Bistro Yacht Club}

The authors found the restaurant menu in Croatian and English language on the Bistro's website accompanied with high quality photos of several typical dishes served in pleasant and fresh ambiance of that restaurant. Reading English version of the menu showed, a correct usage of terminology and simple text without amplification and translation by cultural substitution was used. For example, mentioning a dish Adriatic scampi buzara style while not using additional description/explanation could be quite incomprehensible for a foreign customer. The authors would propose amplification in the form of Adriatic scampi buzara-style cooking where buzara-style would be understood as a way of cooking even if the explanation is not complete. Additional descriptions such as Adriatic scampi buzara-style cooking, Scampi from Kvarner region cooked with olive oil, wine, garlic, breadcrumbs, and fresh herbs would have offered more detailed explanation and would present this dish better to a customer. 
ToSEE - Tourism in Southern and Eastern Europe, Vol. 5, pp. 689-703, 2019

A. Šuljić Petrc, K. Mikinac, I. Edmonds: STRATEGIC APPROACHES TO MENU TRANSLATION ...

Furthermore, the authors noticed an inconsistency of the term usage seafood sauce and fish stock in English (in Croatian temeljac). Fish stock is a base for making soups, chowders, seafood risotto, and any number of sauces but it is completely different from fish sauce because of its preparation and density. The translator used a term seafood sauce only once (at the beginning of the menu!) and later on he/she replaced it with the correct expression fish stock.

Despite the above mentioned lack of amplification this translation strategy was used in a very incorrect way as a dish name - Black risotto made according to the recipe of our grandmothers...the rest is a secret (Croatian version Crni rižoto prema recepturi naših nona...ostalo je tajna). First of all, the name is too long and it would have the same meaning if the name was Black risotto traditionally prepared. Secondly, the final part of the sentence the rest is a secret could provoke suspicion for foreign customers, especially if there are no ingredents and preparation description of the preparation as additional information.

Finally, the authors observed an often usage of French words like a la white pate where accents are missing ( à la white pâté) and obvious tendency of French-English combination that is quite unusual, could have be replaced with cod fish "in white " where keeping in white would belong to Literal Translation strategy but also quite incomprehensive since there is no dish description. Another more simple and comprehensible solution would have be cod fish pâté where reduction of in white would not need additional description. Other French words like veloute instead of velouté and filet instead of fillet represent translator's superficiality using another language expressions without checking the correct spelling.

\subsubsection{Moho}

The authors found the menu on the restaurant's Facebook public profile in a very simple one-page form. The translation is well made despite the fact that there are no additional explanations for dishes because of the presence of dish names which already consist of ingredients. In fact, the description of dish preparation is not needed since the meal offer is very simple. It could be noticed that dry-cured pršut ham could be replaced with $d r y$ cured ham or pršut and amplified with explanation about the provenience of the ham that is homemade traditionally dried. The translation of pršut in English is ham and it seems quite incomprehensible what kind of ham this restaurant is offering. The same thing happens with Pljukanci pasta without additional explanation what the term pljukanci means which provokes incomprehensibility towards the customer. Pljukanci pasta could have been replaced or with Homemade pasta pljukanci or with Homemade hand-rolled pasta pljukanci.

\subsubsection{Bevanda}

The restaurant menu was found on its website in Croatian and English version. The menu design and font reflects the quality of restaurant, even the quantity of borrowed expressions from French language both into Croatian, as well as into English language. The specific usage of terms like balsamic vinegar pearls are more attractive and effective than using balsamic vinegar as everyday ingredient. Finally, there two more mistakes in 
ToSEE - Tourism in Southern and Eastern Europe, Vol. 5, pp. 689-703, 2019

A. Šuljić Petrc, K. Mikinac, I. Edmonds: STRATEGIC APPROACHES TO MENU TRANSLATION ...

English translation which do not only consist in incomprehensibility but in a completely wrong presentation of a dish. Cream of vegetable soup is not the equivalent for Vegetable cream soup. The same happens with the translation of Paška janjetina $\boldsymbol{u}$ teći $=$ Roasted lamb from the island of Pag. Cooked cured meats ( $\boldsymbol{u}$ teći) are heat treated with steam (wet heat treatment). Roasted cured meats (from whole pieces of meat) are roasted in an oven (dry heat treatment).

\subsubsection{Ružmarin}

The restaurant menu in Croatian and English languages are available on the restaurant's website with high quality photos of food amplified with short stories about its history. The translation in English is very good except for the inconsistency in using and translating of a term rucola that is later replaced with rocket salad and is obvious that these two types of salads are completely different. For most dishes, the translator kept the original Croatian name not adding the explanation/description in English, for example: Prošek, ajvar, čevapčići, buzara, etc. All this terms are impossible to understand without any additional explanation and it is quite probable that foreign customers would avoid them. On the other hand, some descriptions are translated completely wrong: blitva na dalmatinski (that would be swiss chard on the Dalmatian style - with boiled potatoes and olive oil), in this restaurant's menu is translated swiss chard with boiled potatoes. Not mentioning olive oil as a very important ingredient that makes this dish preparation unique could be considered as a wrong translation.

\subsubsection{Valle Losca}

The menu has a simple form and the translation is simple but with several completely unacceptable dish names as well as parts of the names that are omitted but essential. In translation of domaći fuži and domaći pukljanci the translator put the same translation homemade pasta that would need additional explanation because the both types of pasta are homemade but their origin and form are different. Furtehrmore, we have interesting names of two dishes that seem to be the titles of some short stories: Istra nam je dala (Istra has given us) and More nam je dalo (The sea has given us) without description of a dish including ingredients and way of preparation. The literal translation seems quite weird even if the above mentioned names could lead to conclusion that these dishes consist of seafood and of typical products that originated from Istria, however a foreign customer would still have no idea what is all about. The culmination of a dish name is certainly Treća sreća (Third time's the charm) that is an idiomatic expression in both languages, still without further explanation.

\subsubsection{Argonauti}

This restaurant's menu in English has big spelling mistakes in its translation - usage of capital letters: mediterranean herbs, grana padano cheese, kvarner scampi, plitvice lakes, istrian truffles. In spite of very correct, comprehensive and detailed explanations of each dish, these spelling mistakes cannot be tolerated, particularly if this is a restaurant in a five-star hotel. 
ToSEE - Tourism in Southern and Eastern Europe, Vol. 5, pp. 689-703, 2019

A. Šljić Petrc, K. Mikinac, I. Edmonds: STRATEGIC APPROACHES TO MENU TRANSLATION ...

\subsubsection{Roko}

The menu is found on the restaurant's website. The menu content is quite complex with variety of dishes. There are a lot of explanations and additional descritptions for dishes that have typical Croatian names (pljeskavica $=$ beef patty, minced meat,...; kulen $=$ kulen salami). Except for this, the translator omitted several important adjectives: umak od goranskih vrganja (sause of mushrooms from the continental Croatia - region Gorski kotar Region) is simplified as a sauce of porcini mushrooms; umak od kvarnerskih kozica (sauce of prawns from Kvarner Region) is simplified as a sauce of prawns. The attractiveness of dishes lies also in the origin of ingredients especially for foreign customers who mostly want to experience the taste of food typical for some country.

\subsubsection{Stancija Kovačić}

The menu was directly obtained from the owners. A simple translation with no additional descriptions or explanations is the main characteristic of this translation. Literal translation like veal steak on a grill (instead of grilled veal steak) correponds with Croatian expression na ̌̆aru.We can also notice simplified translation of dishes comparing Croatian and English version but with several German words instead of English: Fisch and Truffel (fish and truffle).

\subsubsection{Laurus}

The menu was provided directly from the restaurant. It is composed of variety of dishes professionally translated with all additional explanations. At the heading of one menu's page it is written: Please ask your waiter and this is the first menu where the importance of a waiter for additional explanation is directly emphasized. Apart of the well translated menu and grammatically correct descriptions, there is buzara-style adjective with no explanation what buzara means. Another term dry-cured pršut ham could be replaced with dry-cured ham or pršut and amplified with explanation about the provenience of the ham that is homemade traditionally dried. The translation of pršut in English is ham and it seems quite incomprehensible what kind of ham this restaurant is offering.

\subsubsection{Konoba Tramerka}

The authors found the menu on the restaurant's Facebook public profile. Konoba Tramerka is a family restaurant that has a long tradition. The particularity of this Local Cuisine restaurant is the offer of homemade products from regional family farms such as salami, cheese and meat. In their menu, which is simple without descriptions or additional explanations except for some that became the part of a dish name introduced in the brackets. The lack of translation of Croatian names for pljukanci that are simply translated as homemade pasta without stressing its origin. The additional information about the family names that produced dry-ham and some sorts of cheese gives the sensation of offering the food that is hundred percent homemade and typical. 
ToSEE - Tourism in Southern and Eastern Europe, Vol. 5, pp. 689-703, 2019

A. Šuljić Petrc, K. Mikinac, I. Edmonds: STRATEGIC APPROACHES TO MENU TRANSLATION ...

\subsubsection{Remisens Premium Hotel Kvarner}

The menu was provided directly in the restaurant and it was one pleasant surprise for the authors observing the great amount of French culinary expressions in English version of the menu. All these expressions are correctly used but the omission of accents and misspelling in a la Milanesse instead of à la Milanese, and in filet instead of fillet are the only objections for the menu translation in English. Additional information is the presence of the allergens in the brackets bellow each dish.

\subsection{Translation strategies and grammar mistakes}

The first phase was to identify dish names in English language (target language - TL) without previously observing versions in Croatian language (source language - SL). The selected menus were written in Croatian and English language and the analysis was made comparing translations of different menus. The aim was to analyze the menu content from customer's perspective trying to neglect the knowledge of SL. The authors have made a survey about the source of translation - if the menu translation in English was done by the professional translators (translation agency) or by private/unprofessional person who claims to know English (usually the owner, friend or a neighbour or even a chef).

The second phase was to apply translation strategies Al-Rushaidi and Ali (2017) such as Borrowing (strategy used when there is a lack of equivalence and the terms can be borrowed from other languages); Literal Translation (the strategy that preserves the term from the source language and it is difficult to translate itnto the target language); Amplification (strategy when the translator adds some information or expression that are not present in original text); Reduction (strategy that omits the terms considering them inappropriate or complicated for target language); Translation by Cultural Substitution (this strategy is used by the translators where the cultural substitution in translation is needed to explain better the meaning of food items). Moreover, in menu translation analysis of above mentioned restaurants, there is also the observation of grammar mistakes such as misspelling which is the most common mistake in majority of analyzed menus. All mentioned strategies are related to four criteria that Wladyslaw Chlopicki (2018) mentioned: comprehensibility, completeness, economy and carefulness. He also emphasizes that borrowings are acceptable, but they must be used consistently and cannot interfere with comprehensibility. 
ToSEE - Tourism in Southern and Eastern Europe, Vol. 5, pp. 689-703, 2019 A. Šuljić Petrc, K. Mikinac, I. Edmonds: STRATEGIC APPROACHES TO MENU TRANSLATION ...

Figure 2: Review of translation strategies and mistakes

\begin{tabular}{|c|c|c|c|c|c|c|c|c|c|c|c|}
\hline \multirow{2}{*}{$\begin{array}{c}\text { Restaurant's } \\
\text { name }\end{array}$} & \multicolumn{2}{|c|}{ Type of translation } & \multicolumn{5}{|c|}{ Usage of translation strategies. } & \multicolumn{4}{|c|}{ Classification of mistakes } \\
\hline & \begin{tabular}{|l|} 
Professional \\
\end{tabular} & \begin{tabular}{|l|} 
Unprofesssional \\
\end{tabular} & Borrowing & $\begin{array}{c}\begin{array}{c}\text { Literal } \\
\text { translation }\end{array} \\
\end{array}$ & Amplification & Reduction & $\begin{array}{c}\text { Translation } \\
\text { bx cultural } \\
\text { substitution } \\
\end{array}$ & \begin{tabular}{|l|} 
Misspelling \\
\end{tabular} & \begin{tabular}{l|} 
Capital \\
letters
\end{tabular} & Incomprehensibility & Inconsistency \\
\hline Argonauti & $\sqrt{ }$ & & $\sqrt{ }$ & & $\sqrt{v}$ & & $\sqrt{\mathrm{v}}$ & & $\sqrt{ }$ & & \\
\hline Bevanda & $\sqrt{1}$ & & $\sqrt{ }$ & & & & & $\mathrm{V}$ & & $\sqrt{ }$ & $\sqrt{ }$ \\
\hline $\begin{array}{l}\text { Bistro Yacht } \\
\text { Club }\end{array}$ & $\sqrt{ }$ & & $\checkmark$ & $\sqrt{ }$ & & & & $\sqrt{ }$ & & $\sqrt{ }$ & $\sqrt{ }$ \\
\hline $\begin{array}{c}\text { Konoba } \\
\text { Tramerkg }\end{array}$ & & $\sqrt{ }$ & $\checkmark$ & & $\sqrt{ }$ & & $\sqrt{ }$ & $\sqrt{ }$ & & & \\
\hline Laurus & & $\sqrt{ }$ & $\sqrt{ }$ & $\downarrow$ & & & & & & & \\
\hline Moho & $\sqrt{1}$ & & $\sqrt{ }$ & & & & $\sqrt{ }$ & & & $\sqrt{1}$ & \\
\hline $\begin{array}{l}\text { Remisens. } \\
\text { Premium } \\
\text { Hotel } \\
\text { Kvarner } \\
\end{array}$ & $\sqrt{1}$ & & $\sqrt{ }$ & & & & & $\checkmark$ & $\sqrt{1}$ & & \\
\hline Roko & & $\sqrt{ }$ & $\sqrt{ }$ & $\sqrt{ }$ & & $\sqrt{1}$ & & & & $\sqrt{ }$ & \\
\hline Ružmarin & & $\sqrt{ }$ & $\sqrt{ }$ & $\sqrt{ }$ & & $\sqrt{ }$ & & & & $\sqrt{ }$ & $\sqrt{ }$ \\
\hline $\begin{array}{l}\text { Stancija } \\
\text { Kovačićć }\end{array}$ & & $\sqrt{ }$ & $\sqrt{ }$ & $\sqrt{ }$ & & & & $\sqrt{ }$ & & & $\sqrt{ }$ \\
\hline Xalle Losca & & $\sqrt{ }$ & $\sqrt{ }$ & $\sqrt{ }$ & & $\sqrt{1}$ & & & & $\sqrt{ }$ & \\
\hline
\end{tabular}

Here is Figure 2 that represents the data concerning the usage of professional and unprofessional translations, the usage of different translation strategies and the presence of grammar mistakes. It is also shown that $45 \%$ of restaurant's menus were translated by professional translators (translation agencies) and $55 \%$ of restaurant's menus were translated by unprofessional translators (chefs, restaurant owners or friends). From five applied translation strategies, $100 \%$ of application has the strategy of borrowing that shows the problem of lack of equivalence. A large number of borrowing words are coming from French language (fillet, velouté, pâté etc.). The next most applied translation strategy is litteral translation (54\% of restaurants) which used the words and names of dishes that can be considered universal but mostly for the terms and expressions that can be literally translated and such do not change the meaning. The strategy of reduction (27\% of restaurants) and translation by cultural substitution (27\% of restaurants) are strategies that are evenly used. It is worthy to observe that reduction is mostly used by the unprofessional translators. Since this strategy is usually used to avoid some term or expression that is not appropriate in foreign language, in these menus reduction is used to avoid important elements such as origin of some food.

Figure 3: Mistakes in translating restaurants' menus

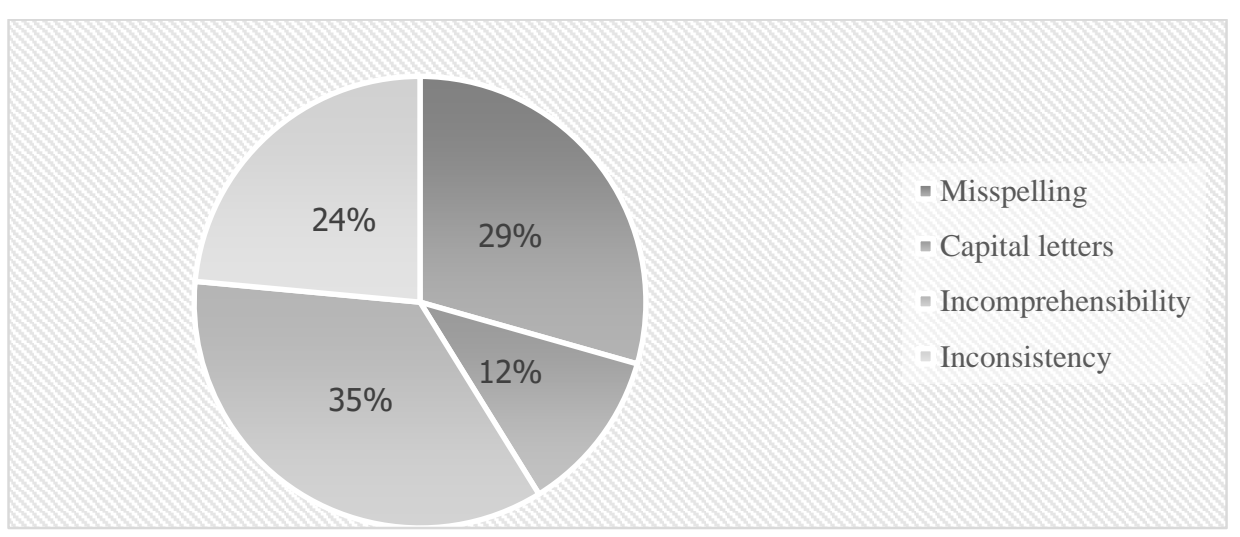


ToSEE - Tourism in Southern and Eastern Europe, Vol. 5, pp. 689-703, 2019

A. Šuljić Petrc, K. Mikinac, I. Edmonds: STRATEGIC APPROACHES TO MENU TRANSLATION ...

In Figure 2 and Figure 3 the authors divided the presence of mistakes and a pie chart statistics of mistakes. Misspelling is the most spread mistake (29\%) together with incomprehensibility $(35 \%)$. Usage of capital letters is present in only two restaurants $(12 \%)$ and the menus of both of them were translated by professional translators. Incomprehensibility and inconsistency can be connected with usage (or not usage) of some translation strategies such as literal translation, reduction and amplification.

\section{CONCLUSION AND DISCUSSION}

This research paper analyzed the most visited restaurants in one of the leading tourist region in Croatia trying to focus on how the translations in English language can provoke misunderstandings and lack of essential knowledge connected not only with scarse language background but also with the professional/culinary expertise.

In the process of obtaining the menus and information about the menu translators, the direct contact of restaurant owners, managers and even waiters and chefs was inevitable. The majority of them admitted the problem of incorrect translations which they discovered by the customers' remarks and observations. The reasons for it were mainly related with the fact that the translations of restaurant menus are not considered as an important part of an offer but just as something that is traditionally present in the restaurants. Because of this, finding cheaper solutions such as hiring the unprofessional translators rather than professional and experienced ones, seems quite spread practice among the restaurant owners. On the other hand, the results of this research showed that even the menus translated by professional translators are not completely correct.

The problem of having an adequate and correct translation of restaurant menus is wellknown amongst the researchers who are dealing with this topic. Inappropriate attitude towards the importance of correct menu translation can result in decreasing quality offer of a restaurant. According to Mills and Thomas (2008) the resturant menus significantly influence the customers' perceptions of a restaurant.

However, the problem of an adequate and correct restaurant menu translations are definitely marginalized. The appropriate knowledge of foreign language and gastronomic background needs to be united in order to produce quality translation. Strategic approaches to menu translations are many and translation strategies can be considered as problem-solving devices. In this research are used the strategies proposed by the researchers Al-Rushaidi and Ali (2017) who applied them in analyzing linguistic and cultural dilemmas in translating food menus from English into Arabic.

Having in mind Gentzler's statement (2001) that menus must treat food items like medical or legal terminology, in an accurate and appropriate manner, in order to be truthful to the source text and to present customers with a faithful translation that fulfils its intention, the analyzed translations (the majority of them) have not offered functional (2008), adequate (1984-1996) and quality text (Colina, 2008). 
ToSEE - Tourism in Southern and Eastern Europe, Vol. 5, pp. 689-703, 2019

A. Šuljić Petrc, K. Mikinac, I. Edmonds: STRATEGIC APPROACHES TO MENU TRANSLATION ...

Given the analysis of existing theories, models of translation strategies, and mistakes made in the restaurant menus translations, the present research tried to analyse and apply the existing theories and models of the translation strategies in eleven highest rated restaurants in Kvarner Region - Opatija. Analysing their menus the authors confirmed that there are still restaurants which entrusted their translations to unprofessional translators. In the author's opinion having menus that consist in serious grammar mistakes, such as not using capital letters for a fixed name adjectives and geographical names of regions, ommissions of important parts of food origins, and misspelling produce the menus that are not comprehensible and in which customers can not trust. The fact is that a high quality translation affects the customer's requirements and ensures that such translations are in the interest of the hospitality facilities' owners, as well as it introduces them professionally, taking into account the content of the translated dishes and its design.

Conditions of doing business in hospitality are changing rapidly. In the last decade has witnessed a substantial growth and rapid change, globally as well as domestically. Customer satisfaction become a critical issue in the success of any business system, hence one of the key challenges in hospitality is how to satisfy and retain customers. In order for restaurants to grow and survive, they must find new ways of thinking, new ways of communication, which has led to various marketing researches, especially those related to customer satisfaction.

The authors also noticed the tendency of restaurant owners and managers to present the customers visually quality menus not so much paying attention of accurate and correct content of menu translation. The restaurant menus are mostly simple without amplifications of dishes (such as description of typical local cuisine food or preparation process) which causes not only misunderstanding but also unnecessary simplification of menu items. Even if it is a fact that quantity does not necessarily means quality, in this case quality of restaurant menu translations can rise the quality level of restaurant offer.

The main contribution of the paper is the analysis of the menu translations and present strategies for translating which influence on service quality and customer satisfaction. Also, there should be a book of guidelines for menus that would contain standards for the meals that are translated. That would create unity between different menus, standardize the language where, for example, the names of different typical dishes would be translated in English in a manner to be understandable to everyone. The result would be improving the quality of the translation which would lead to higher standards of services. It would relieve the waiters from explaining the dishes and that kind of menus would become their learning tool for them. Finally, high quality translation menus would contribute in developing and improving of tourism and hospitality industry of a particular country.

The authors used strategic approaches to menu translations according Al-Rushaidi and Ali primarily to discover the different strategic approaches in translating restaurant menus highliting common grammar mistakes. The research findings are an important contribution to future research of the menu translations and restaurant offer in the Kvarner restaurants. 
ToSEE - Tourism in Southern and Eastern Europe, Vol. 5, pp. 689-703, 2019

A. Šuljić Petrc, K. Mikinac, I. Edmonds: STRATEGIC APPROACHES TO MENU TRANSLATION ...

\section{REFERENCES}

Al-Rushaidi, S.M.S., and Ali, H.I.H. (2017), "Translating food menus from English into Arabic: linguistic and cultural dilemmas", AWEJ for Translation and Literary Studies, 1(1), pp. 201-212.

Beldona, S., Buchanan, N., Miller, B.L. (2013), "Exploring the promise of e-tablet restaurant menus", International Journal of Contemporary Hospitality Management, 26(3), pp. 367-382 doi: 10.1108/IJCHM-01-2013-0039

Bowen, J.T. and Morris, A.J. (1995), "Menu design: can menus sell", International Journal of Contemporary Hospitality Management, 7(4), pp. 4-9.

Chiaro, D., Rossato, L. (2015), "Food and translation, translation and food", The Translator, 21(3), pp. 237243, doi:10.1080/13556509,2015.1110934

Chłopicki, Władysław (2018), "Translation of menus: Labour of Sisyphos, squaring the circle or marrying water and fire?" Folklore (14060957), Vol. 71, pp. 155-178.

Cho, H., Kinny, D., \& Lin, D. (2013), "Parallel Prototyping for Multi-language Service Design: A Case Study on Introducing a Multilingual Tool into a Japanese Local Restaurant", 2013 International Conference on Culture and Computing, doi:10.1109/culturecomputing.2013.23

Cohen, E., Avieli, N. (2004), "Food in Tourism: Attraction and Impediment", Annals of Tourism Research, 31(4), pp. 755-778. doi:10.1016/j.annals.2004.02.003

Colina, S. (2008), "Translation Quality Evaluation: Empirical Evidence for a Functionalist Approach", The Translator, 14 (1), pp. 97-134.

Dabbaghian, A. (2014), "Translation and Tourism: A Cross Cultural Communication and the Art of Translating Menus", Journal of Basic and Applied Scientific Research, 4(4), pp. 11-19. https://www.textroad.com/pdf/JBASR/J.\%20Basic.\%20Appl.\%20Sci.\%20Res.,\%204(4)1119,\%202014.pdf (10.08.2018)

Duran Munoz, I. (2011), "Tourist Translations as a Mediation Tool: Misunderstandings and Difficulties", Cadernos de Tradução, 1(27), pp. 29-49. doi: 10.5007/2175-7968

Fuentes-Leque, A. (2016), "An approach to analysing the quality of menu translations in southern Spain restaurants", Journal of Multilingual ans Multicultural Development, 38(2), pp. 177-188. doi:10.1080/01434632.2016.1187154

Gentzler, E. (2001), Contemporary Translation Theories, Multilinual Matters, Clevedon.

Ghafarian, M., Kafipour, R., Soori, A. (2016), "Domestication and Foreignisation Strategies in Restaurant Menu Translation", Pertanika Journals Social Sciences and Humanities, 24(4), pp. 1417-1429. https://www.researchgate.net/publication/311816390_Domestication_and_Foreignisation_Strategi es_in_Restaurant_Menu_Translation

Gleitman, L., \& Papafragou, A. (2005), "Language and thought”, In K.J. Holyoak, \& R. G. Morrison (Eds.) The Cambridge Handbook of Thinking and Reasoning, Cambridge University Press, New York, pp. 633-661.

Hongyang, Bi (2017), “The impact of using a foreign-language in restaurant menus on customers' attitude and behavioural intention", Master of International Hospitality Management, Auckland University of Technology.

Horvatić, A., Bačić, L. (2013), Nove tehnologije kao promotori turizma i gastronomske ponude Hrvatske, https://hrcak.srce.hr/130307 (12.07.2018)

Kalenjuk, B., Tešanović, D., Banjac, M. (2016), "Struktura i dizajn jelovnika u ugostiteljstvu Srbije kao značajnog prodajnog sredstva u turizmu”, Turističko poslovanje, No. 18, pp. 91-98. doi:10.5937/TurPos1618091K

Lessel, P., Bohmer, M., Kroner, A., Kruger, A. (2012), "User Requirements and Design Guidelines for Digita Restaurant Menus", 7th Nordic Conference on Human-Computer Interaction: Making Sense Through Design, pp. 524-533. doi:10.1145/2399016.2399096

Li, S. (2019), "A corpus-based multimodal approach to the translation of restaurant menus", Perspectives, 27(1), pp. 1-19.

McCall, M. and Lynn, A. (2008), "The effects of restaurant menu item descriptions on perceptions of quality, price, and purchase intention", Journal of foodservice business research, 11(4), pp. 439-445.

Mills, J.E., and Thomas, L. (2008), "Assessing customer expectations of information provided on restauran menus: A confirmatory factor analysis approach", Journal of Hospitality \& Tourism Research, 32(1), pp. 62-88.

Mills, Juline E., Thomas, L. (2008), “Assessing Customer Expectations of Information Provided On Restauran Menus: A Confirmatory Factor Analysis Approach", Journal of Hospitality and Tourism Research, 32(1), pp. 62-88. https://doi.org/10.1177/1096348007309569

Munoz, I.D. (2011), "Tourist translations as a mediation tool: misunderstandings and difficulties", Cadernos de tradução, 1(27), pp. 29-49. 
ToSEE - Tourism in Southern and Eastern Europe, Vol. 5, pp. 689-703, 2019

A. Šuljić Petrc, K. Mikinac, I. Edmonds: STRATEGIC APPROACHES TO MENU TRANSLATION ...

Ozdemir, B., and Caliskan, O. (2014), "A review of literature on restaurant menus: Specifying the managerial issues", International Journal of gastronomy and food science, 2(1), pp. 3-13.

Pouget, C.F. (2000), “Are Menu Translations Getting Worse?: Restaurant Menus in English in the Tarragona Area", Target. International Journal of Translation Studies, 12(2), pp. 323-332.

Reiss, K. and Vermeer, H.J. (1984-1996), Grundlegung einer allgemeinen Translationtheorie, Tubingen: Niemeyer.

Reynolds, D., Merritt, E.A., and Pinckney, S. (2005), "Understanding menu psychology: An empirical investigation of menu design and consumer response", International Journal of Hospitality \& Tourism Administration, 6(1), pp. 1-9.

Trostler, N., and Gvion, L. (2007), "Trends in restaurant menus: 1950-2000”, Nutrition today, 42(6), pp. 255 262.

Vorajaroensri, Panida. (2002), An Analysis of Translation Strategies Used in Thai Restaurant Menus, Master's Project, M.A. (English). Bangkok: Graduate School, Srinakharinwirot University. Advisor Committee: Assist. Prof. Dr. Tipa Thep-Ackrapong, dr. Nitaya Suksaeresup and Mr. Brett Heagren.

Walters, C.G. (1978), Consumer Behavior: Theory and Practice, Homewood, Richard D. Irwin, In.

Wansink, B., Painter, J., \& Ittersum, K.V. (2001), "Descriptive Menu Labels' Effect on Sales", Cornell Hotel and Restaurant Administration Quarterly, 42(6), pp. 68-72. doi:10.1177/0010880401426008

Webster's Online Dictionary (2019), Definition of customer. Taken on February 28, 2019, from https://www.merriam-webster.com/dictionary/customers

Webster's Online Dictionary (2019), Restaurants in Opatija. Taken on February 28, 2019, from https://www.tripadvisor.com/Restaurants-g297515-Opatija_Primorje_Gorski_Kotar_County.html

Alenka Šuljić Petrc, PhD, Lecturer

University of Rijeka

Faculty of Tourism and Hospitality Management

Department of Foreign Languages in Business

Primorska ulica 42, p.p. 97, 51410 Opatija, Croatia

Phone: +3859151574 44

E-mail: alenkasp@fthm.hr

Krešimir Mikinac, $\mathrm{PhD}$, Assistant Professor

University of Rijeka

Faculty of Tourism and Hospitality Management

Department of Hospitality, Gastronomy and Restaurant Business

Primorska ulica 42, p.p. 97, 51410 Opatija, Croatia

Phone: +385915551006

E-mail: kmikinac@fthm.hr

Ivana Edmonds, M.A.(Ed), M.Ed, Lecturer

Language Stars Centar, School of languages

Šetalište 13. divizije 20, 51000 Rijeka

Phone: +385 981307743

E-mail: ivana.edmonds@hotmail.com 